\title{
UUE AASTATUHANDE ROMAANIVÕISTLUSED: ARVESTATAV HÜPPELAUD
}

1.

Romaanivõistlus on Eestis olnud juba peaaegu kaheksakümmend aastat kirjanduse elavdamise ja populariseerimise vorm, omades kindlat kirjandusloolist tähendust. Siinne kirjatükk võtab eesmärgiks vaadelda võistluse ajaliselt hilisemat otsa - ennekõike uue aastatuhande romaanivõistlusi. Keskendun Eesti Romaaniühingu korraldatud võistlustele, mis on nimetatud ajaperioodil toimunud viiel korral, ning lisaks mullusele Eesti Kirjanike Liidu korraldatud võistlusele, kuna seda võib pidada romaaniühingu tegevuse mantlipärijaks. Algselt Eesti Romaanifondi nime kandnud ühing jõudis alates 1996. aastast läbi viia seitse võistlust. Nullindate lõpus pöördus romaaniühingu juhatus palvega minu ja Peeter Helme poole, et meie kui noorema põlvkonna inimesed võistluste organiseerimise üle võtaksime. Pärast inetult pikaks veninud pausi liitus meiega Tiit Aleksejev ning me viisime kunagi antud lubaduse lõpuks ellu. Riivamisi vaatlen ka alates 2008. aastast korraldatud kirjastuse Tänapäev võistlusi, mis on siiani toimunud viiel korral, kuid jätan põhjalikuma käsitluse kellelegi teisele, kuna kahe romaanivõistluse vahelised ühendusteed paistavad mu meelest moodustavat eraldi teema. Oleks näiteks huvitav uurida, mil määral käsikirjad nende vahel ringlevad. Selge, et päris mitmed märkimist leidnud autorid liiguvad ühelt võistluselt teisele ja on saanud tunnustatud mõlemal konkursil (näiteks Eia Uus, Märt Laur, Helen Eelrand või Helju Pets). Samas paistavad Tänapäeva võistlusel olevat „oma” autorid (tuntumatest näiteks kaks korda esiotsa kerkinud Ketlin Priilinn).

Põhiküsimus, millel aga tahaksin järgnevalt peatuda, kõlab nii: mil määral annavad romaanivõistluse tööd tooni siinse kirjanduse üldpildis?
2.

Nagu mainitud, on uuel aastatuhandel leidnud aset kuus romaaniühingu ja kirjanike liidu romaanivõistlust. Olgu need koos auhinnatud teostega mälu värskendamiseks siin ka ära toodud.

2000. aasta võistlus:

I - Aarne Ruben, „Volta annab kaeblikku vilet";

II - Leo Kunnas, „Sõdurjumala teener”; III - Maimu Veske, „Continental” ja Lehte Hainsalu, „Kellakuuljad”.

Kõik nimetatud teosed avaldati 2001. aastal.

2002. aasta võistlus: I - Nikolai Baturin, „Kentaur”; II - Indrek Hargla, „Vabaduse kõrgeim määr";

III - Enn Põldroos, „Joonik kivi”.

Kõik nimetatud teosed avaldati 2003. aastal.

2004. aasta võistlus:

I - Sass Henno, „Mina olin siin”;

II - Olavi Ruitlane, „Kroonu” (võistluseaegne pealkiri oli „Kaval-Peeter ja VenePagan");

III - Meelis Friedenthal, „Kuldne aeg”. Kõik nimetatud teosed ilmusid 2005. aastal.

2006. aasta võistlus:

I - Tiina Laanem, „Väikesed vanamehed";

II - Olle Lauli, „Niguliste õpilased”;

III - Aarne Biin, „Linna valitsemine”.

Kõik nimetatud teosed ilmusid 2007. aastal.

2008. aasta võistlus:

I koht jäeti välja andmata;

II - Milvi Martina Piir, „Liblikad janus”; III - Birk Rohelend, „Minu sõraline sõber” ja Marion Andra, „Algolagnia”. 
Kõik nimetatud teosed avaldati 2009. aastal.

2015. aasta võistlus:

I - Armin Kõomägi, „Lui Vutoon”;

II - Märt Laur, „Lahustumine”;

III - Jim Ashilevi, „Kehade mets”;

IV - Helen Eelrand, „Suluseis”.

Kõik raamatud ilmusid võistlusega samal aastal.

\section{3.}

Üks võimalus vaadata romaanivõistluse võidutööde positsiooni üldises kirjanduspildis on uurida, mil määral leiab pärjatud teoseid Eesti iga-aastaste kirjandusauhindade nimistutes. Tundub, et lakmuspaberiks sobivad näiteks Eesti Kultuurkapitali kirjanduse sihtkapitali auhinnad, mille praktikasse kuulub nullindate algusest ka nominentide väljakuulutamine. Loomulikult ei tasu unustada teisigi kindla ajavahemiku (põhiliselt aasta) lõikes kogu eesti proosat haaravaid tunnustusi.

Sellises võrdluses tõuseb kohe esile üks nullindate romaanivõistluste võidutöö - Nikolai Baturini „Kentaur”, mis pälvis 2003. aastal ühtlasi kultuurkapitali proosaauhinna. Nominentide hulka jõudis samal aastal ka Indrek Hargla, aga mitte võistlusel teise koha pälvinud „Vabaduse kõrgeima määraga”, vaid romaaniga „Palveränd uude maailma”. On selge, et „Kentaur” mängib olulist rolli nii Baturini isiklikus biograafias kui ka nullindate kirjanduses üldisemalt. Seda mastaapset romaani annab võrrelda teiste Baturini suurteostega, samuti ei saa romaanist üle ega ümber seoses autori avarilma kontseptsiooniga - kui näiteks „Karu südant” võib pidada taigaromaaniks, siis „Kentaur” kasutab avarilma motiivina kõrbe. Kuigi Baturin tegutses nullindatel päris viljakalt, ei ulatu ükski tema sel ajavahemikul ilmunud romaan tähenduse ja kaalu poolest „Kentauri” kõrvale. Tõsi, Baturini tähendus eesti kirjanduses kipub olema eraldi teema, tema loomingu vastuvõtus pole raske märgata veelahet, kus ühele poole jäävad innustunud pooldajad ja teisele poole halvasti varjatud ükskõiksus. Vastuolu tuli hästi nähtavaks näiteks seoses 2009. aasta kulka žanriauhindade lõppnimekirjaga, kus žürii otsustas esile tõsta vaid nelja prosaisti kuue võimaliku asemel. Selline hinnang proosa-aastale tekitas vastukaja. Kuna tol aastal ilmus teiste hulgas Baturini romaan „Delfiinide tee”, mis nominentide hulka ei pääsenud, andis juhtunu mitmele Baturini pooldajale põhjuse žürii proosanimekirja kritiseerida. Berk Vaher, üks Baturini innukamaid eestkõnelejaid, kirjutas Loomingus aastat kokku võttes ja žürii valikut teravalt kahtluse alla seades, et Baturini looming on „eesti literaadi maailmapildi jaoks ikka veel liiga suur" (Vaher 2010: 415).

Olgu selguse huvides ära mainitud, et žüriile heideti ette teistegi algupäraste proosateoste eiramist, kuid Baturin tõusis esile kui erakordne anne, keda ei osata kodumaal tunnustada. Üks Baturini pooldajate levinumaid retoorilisi võtteid seobki tema loomingu maailmakirjandusega, eesti kolkliku kirjakultuuri jaoks liiga suurejoonelise vaimulaadiga. Näiteks Toomas Vint kirjutas 2009. kirjandusaastat kokku võttes ning just „Delfiinide teed” esile tõstes järgmist: „Kui olin Baturini suurepärase raamatu läbi lugenud, hakkas mind vaevama kuri eelaimdus, et see on liiga vägev teos eesti väikese kirjanduse jaoks" (Vint 2010). Siinse loo põhiteema juurde tagasi pöördudes võib rõhutada, et just „Kentauri” korduv pärgamine kujutab endast seda õnnelikku hetke, mil tema poolehoidjate kujutlus autori suurusest kattus tegeliku olukorraga. Ühtlasi on „Kentaur" üks neid eepilisi raamatuid, mis võimendavad romaanivõistluse laiemat tähendust, sidudes seda tugevalt eesti kirjanduse üldpildiga.

Teine nullindate romaanivõistlustel pärjatud töö, mis laiemat tunnustust leidis, oli Olavi Ruitlase „Kroonu”. Kuigi 2004. aasta romaanivõistluse kon- 
tekstis jäi see alla Sass Henno teosele „Mina olin siin”, oli „Kroonu” samas ainus võistlusel esile tõstetud romaan, mis jõudis 2005. aasta kulka proosaauhindade nimistusse. Huvitav, et ka tol aastal tekkis lõppnimekirja ümber kõva poleemika, kuna žürii otsustas jätta proosaauhinna välja andmata, pärjates selle asemel kaht luuleauhinnale kandideerinud kogu: Kristiina Ehini „Kaitseala” ja Jürgen Rooste "Ilusaks inimeseks". Kuna auhinnastatuudi praegune versioon sellist ümbermängimist enam ei võimalda, on huvitav hetkeks spekuleerida, millisele proosateosele oleks preemia tol aastal läinud. „Kroonu” tundub ajaliseltki distantsilt arvestatav pretendent. Igal juhul pälvis teos lisaks kulka proosaauhinna lõppvalikus figureerimisele ka 2006. aasta Virumaa kirjandusauhinna ja nüüdseks hingusele läinud Eesti Raudtee ja Sirbi kirjanduspreemia (kahasse Kristiina Kassi lasteraamatuga „Kasper ja viis tarka kassi”). Tänu elavale vastukajale kinnistas "Kroonu” Ruitlase rolli tõsiselt võetava prosaistina. Ruitlane on autor, kes avaldab romaane harva, kuid 2015. aastal ilmunud ja väga sooja vastuvõtu osaliseks saanud „Vee peal” kinnitab, et „Kroonu” polnud tema loomingus juhuslik õnnestumine ning et Ruitlane kuulub nende harvade eesti autorite hulka, kes köidab nii kriitikuid kui ka laiemat lugejaskonda. See sai mu meelest alguse „Kroonust”.

Kolmas teos, mis on tõusnud esile nii romaanivõistluse kui ka iga-aastaste auhindamiste kontekstis, on Leo Kunnase „Sõdurjumala teener” (mis, tõsi küll, ilmus 2001. aastal koos kümme aastat varem avaldatud „Kustumatu valguse maailmaga”). Raamat kandideeris kulka proosaauhinnale ning pälvis 2002. aastal kahasse Ülar Ploomi luulekoguga „Üks ja kogu” Betti Alveri nimelise parima debüütteose preemia. Mis puudutab kulka nominatsiooni, siis mäletatavasti kuulus 2001. kirjandusaasta Mehis Heinsaarele, tema kaks jutukogu „Vanameeste näppaja” ja „Härra Pauli kroo- nikad" napsasid endale ka kulka proosapreemia. Huvitav tundub jällegi tõsiasi, et romaanivõistluse teise koha töö jõudis küll proosaauhinna esiviisikusse, esikoha pälvinud teos aga mitte.

Neljas ,juhtum” - Armin Kõomäe „Lui Vutoon”, 2015. aasta romaanivõistluse esikoha omanik - kandideeris samuti kulka proosapreemiale. Siinse loo ilmumiseks on juba selgunud, et „Lui Vutoonil” ei õnnestunud „Kentauri” kõrvale kerkida, sestap jääb Baturini romaan praeguse seisuga omamoodi pretsedendiks, erandiks, mis on tõusnud esikohale nii romaanivõistluse kui ka terve kirjandusaasta kontekstis.

Romaanivõistluste tulemusi iga-aastaste tunnustustega võrreldes leiab veel kaks huvitavat „juhtumit”. Teatavasti on võistluse žüriidel kombeks tõsta lisaks auhinna pälvinutele esile ka märkimist või ergutusauhinda väärivaid teoseid, mille arv on vaadeldaval perioodil pendeldanud nelja ja kümne vahel. Märkimise või ergutuseni jõudnud romaanide seast võib leida kaks nimetust, mis pälvisid pärast romaanivõistluse žürii tunnustust olulise kirjandusauhinna: Wimbergi debüütromaan „Lipamäe” ning Eia Uusi debüütromaan „Kuu külm kuma”. Esimene sai 2002. aastal Virumaa kirjandusauhinna, teine teos pärjati 2006. aastal Eduard Vilde nimelise kirjandusauhinnaga.

Remargi korras võib heita pilgu samale suhtele ka kirjastuse Tänapäev võistluse kontekstis. Ainus teos, mis on pälvinud kirjastuse heakskiidust laiemat tunnustust, on 2015. aasta võistlusel esikoha pälvinud Kaur Riismaa romaan „Pimeda mehe aiad”, mis kandideeris tänavu koos Riismaa teise romaaniga „Pühamägi” (ning loomulikult koos „Lui Vutooniga") kulka proosapreemiale.

Mainitud kuue (koos Tänapäeva võistlusega seitsme) nimetusega kattuvus ülejäänud auhindadega piirdub. On raske hinnata, kas seda on palju või vähe. Kindlasti välistavad kattuvused mõtte romaanivõistluse marginaalsusest, pi- 
gem vastupidi. Samuti saab öelda, et romaanivõistlusel osalenud teose laiem tähendus ei pruugi piirduda ainult nähtavusega auhindamistel. Ühe hea näite võib tuua 2007. aastast, mil ilmusid ka 2006. aasta romaanivõistluse kesksed tööd. Ükski neist ei jõudnud kulka proosaauhinna lõppvalikusse, kuigi võistluse taset ei saa kindlasti madalaks pidada. Üks põhjusi seisnes tõsiasjas, et 2007. aastat iseloomustas erandlikult tihe konkurents. Mäletatavasti ilmusid tol aastal mitmed romaanid, mis andsid tooni kogu kümnendile ning mille mõju pole siiani vähenenud: näiteks Andrus Kivirähki „Mees, kes teadis ussisõnu”, Ene Mihkelsoni „Katkuhaud” ja Jaan Kaplinski „Seesama jõgi”. Kõik nimetatud raamatud kandideerisid ka kulka proosaauhinnale, mille pälviski lõpuks „Katkuhaud”. Sestap ei ole imestada, et romaanivõistlusel esile tõusnud nimed, nagu Tiina Laanem, Olle Lauli ja ka Peeter Helme, kelle „Puudutus” jäi toona napilt auhinnakohast ilma, ei pääsenud oma debüütidega proosaauhinna lõppvalikusse. Ometi leidis näiteks Olle Lauli „Niguliste õpilased” endale prominentseid eestkõnelejaid. Märt Väljataga, tõmmates ajakirjas Looming kokku seal aset leidnud nullindate kirjanduse ümber toimunud arutelu ja püüdes „unustusest päästa” teoseid, „ilma milleta oleks pilt nullindate elust ja kirjandusest märksa vaesem", tõstab teiste hulgas esile Lauli romaani, mis on tema sõnul „mõjuv ja representatiivne pilt nn. grilliajastust" (Väljataga 2010: 722). Väljataga ettevaatlik, kuid pidev toetus on ennast õigustanud, kuna Lauli teine romaan „Kodutus” pälvis 2012. aastal kulka proosaauhinna.

\section{4.}

Eelöeldu põhjal peab vaagima kaht järeldust. Esiteks - positsioon romaanivõistluse tulemustes ei ole kaugeltki üheses seoses teose hilisema menu või olulisusega. Teiseks - romaanivõistlusel on kindlasti laiem tähendus, aga see paistab samas olevat omajagu spetsiifiline.

Laiendan esimest järeldust. Romaanivõistluse tulemuse ja teose hilisema või laiema tähenduse vahel võib ilmneda erinevaid pingeid. Selgelt tuleb välja, et võistluse võidutöö võib hiljem, avaramas kontekstis, jääda mõne võistlusel madalamalt hinnatud romaani varju. Nii näiteks tundub Kunnase „Sõdurjumala teener" mängivat nullindate kirjanduses mõnevõrra olulisemat rolli kui Rubeni „Volta annab kaeblikku vilet”. Sama lugu on Lauli „Niguliste õpilastega”, mis jäi 2006. aasta võistlustel alla Tiina Laanemi romaanile „Väikesed vanamehed”, aga osutus hiljem kirjanduslikult kõnekamaks. Laanem tuli oma võidutööga küll jõuliselt pildile, „Väikestest vanameestest" sai müügihitt, ent praeguseks ei kõla Laanemi nimi tugevalt kaasa mitte enam pikema proosa, vaid hoopis novellikirjanduse ja ennekõike näitekirjanduse kontekstis. Tõsi, see ei lahjenda mingilgi määral tõsiasja, et Laanem ilmus eesti kirjandusse just romaanivõistluse kaudu.

On ka juhtunud, et romaanivõistluste tulemustes auhindamata jäänud teos omandab hiljem kõiki toonaseid konkurente varjutava tähenduse. 2008. aasta võistlusel, kus teatavasti jäeti esimene auhind välja andmata, eraldati ka ergutusauhindu, millest üks läks Robert Kurvitza käsikirjale „Püha ja õudne lõhn”. Kui enamasti ilmuvad romaanivõistluse tugevamad tööd aasta pärast võistlust (ning 2015. aastal koguni võistlusega samal aastal), siis Kurvitz viimistles käsikirja tunduvalt kauem ning avaldas selle raamatuna alles viie aasta pärast. Kohe pärast ilmumist hakkas romaani ümbritsema kultusteose oreool. Kurvitzat, kes on siiani rühmituse ZA/UM üks tuntumaid nimesid, toetas valjuhäälne sõpruskond, mõttekaaslaste ring. Internetisaidil Goodreads kirjutas Nuke Darker (aka Kaur Kender) järgmiselt: „See on üsna nagu Gabriel García Márquez'i „Sada aastat üksildust”. Aga 
Robert Kurvitz on oluliselt enesekindlam, kui noor Gabriel García Márquez oli - Robert ei viska kogu aeg nalja, ta ei ole nalja asi. [---] See raamat kingib eesti keelele sada aastat juurde.” Jättes kõrvale võrdluse García Márquezega - juba mainitud 2009. aasta proosa ülevaates võrdleb Toomas Vint sama autoriga Nikolai Baturinit -, tuleb märkida, et tegu polnud ainsa nõnda kiitva iseloomustusega. Raamatu kõlapinda võimendas Sirbi skandaal, milles autor aktiivselt (ja selgus, et toimetajana ebaõnnestudes) osales. ZA/UM esitas Kurvitza romaani lausa kui omamoodi manifesti, laiema kultuuripoliitilise meelelaadi ilukirjanduslikku vastet. Ometi ei piirdunud kiidukoor ainult omainimestega, olgugi et Kenderile omase mõõdutundetuseni keegi teine ei ulatunud. Kindlasti tasub märkida Jaak Tombergi põhjalikku käsitlust, kust ta määratleb „Püha ja õudset lõhna” kui „fantastilist realismi” (Tomberg 2014). Igatahes tõestab Kurvitza esikteose fenomen veenvalt, et romaanivõistluselt tulnud raamat võib kergesti hakata elama kirjanduse üldpilti ergastavat elu, ilma et varasem võistluse kontekst enam tooni annaks.

\section{5.}

Nüüd teisest järeldusest - romaanivõistluse laiemast, aga samas spetsiifilisest rollist. See tundub olevat seotud küsimusega, millised kirjanikud õieti romaanivõistlustel osalevad. Osalt ei ole sellise küsimusepüstitusega suuremat midagi peale hakata, kuna üks võistluse kriteeriume on olnud käsikirjade anonüümsus. Ikka jääb võimalus - ükskõik kui ebatõenäoline -, et nii mõnigi nimekas eesti kirjanik, kelle nime võistluse nimekirjades ei kohta, on sellel ometi kas või ühe korra osalenud. Olemata psühholoog, julgen arvata, et juba endale nime teinud kirjanikule võib anonüümne konkurents olla raskem kui debütandile, kuigi nullindategi romaanivõistluselt leiab kindlasti oma „veteranid”: lisaks Baturinile näiteks Lehte Hainsalu või
Aarne Biin. Hainsalu „Viis minutit enne vihma” ja Baturini „Apokalüpsis anno Domini...” pälvisid mõlemad 1996. aasta võistlusel teise koha, Hainsalu leidis märkimist ka 1998. aastal. Kui vaadata nullindate võistlusi, siis tähenduslikult mõjub kahtlemata Mehis Heinsaare osalus. Heinsaar, nullindate alguses korduvalt auhinnatud novellikirjanik, osales 2004. aasta võistlusel, kus märgiti ära tema töö „Artur Sandmani lugu”. Hiljem, kui romaanidebüüt 2005. aastal ilmus, pälvis see üsna jaheda vastuvõtu, mis ajas marru Heinsaare apologeedi Berk Vaheri, kes „eksinuid” kohati lausa demagoogiliste võtetega ründas. Tõsi aga on, et „Artur Sandmani lugu” on siiani jäänud Heinsaare ainsaks romaaniks ning pisut hiljem jätkas ta edukalt nii novellikirjanikuna (2007. aastal ilmunud „Rändaja õnn” kandideeris juba mainitud Kivirähki, Kaplinski ja Mihkelsoni kõrval kulka proosapreemiale) kui ka luuletajana.

Niisiis esindab Heinsaar juba endale nime teinud, aga sellegipoolest romaanivõistlusel osalenud prosaistide vähemust. Miks vähemust? Sest vähemalt nullindate võistlusi jälgides pole raske märgata (proosa)debütantide rohkust.

Romaanivõistluse kaudu ühel või teisel moel debüteerinud autorite hulk ja nimekiri on muljet avaldav. Liikugem kronoloogiliselt. 2000. aasta võistlusel esile tõstetud käsikirjade hulgast tuli kolm esikteost: Maniakkide Tänava „Mu aknad on puust ja seinad paistavad läbi”, Maarja Oderi „Inglinägu” ning Erik Tohvri „Majad jõe ääres”. Muide, jäin korraks kahtlema, kas tõepoolest on Tohvri nõnda hiline debütant, aga ka e-kataloogi ESTER andmetel oli 2001. aastal ilmunud „Majad jõe ääres” tol hetkel 68-aastase autori esikteos. Lisaks mainitutele oli kahe tunnustatud käsikirja, Aarne Rubeni võidutöö ja Wimbergi „Lipamäe” näol tegemist proosadebüüdiga. Rubeni ja Wimbergi esimesed autoriraamatud olid luulekogud: Ruben debüteeris 1993. aastal Tõnu Õnnepalu 
koostatud koguga „Raevule” ning Wimberg palju tähelepanu pälvinud „Maaaraamatuga" 2000. aastal. Äramärgitud tööde hulgas tasub mainimist ka Indrek Hargla, kelle „Baiita needus” pole küll debüüt (milleks oli 2000. aastal ilmunud „Nad tulevad täna öösel”), kuid kelle aeglasel, ent järjekindlat tõusul ulmehuviliste ringist laiemasse teadvusse ei tohi romaanivõistluste osa kindlasti alahinnata.

2002. aasta võistlusel esile tõusnud käsikirjade hulgas oli kolm debüüti, neist kaks füüsilise raamatu kujul: Marje Ernitsa „Õpetaja, õpetaja” ja Leida Rebase „Üle väljamäe”. Kui Ernits hakkas pärast seda väga tihedalt avaldama, siis Rebase esikraamat ongi siiani jäänud tema ainsaks. Märkimist leidnud teoste seast leiab ka ühe proosadebüüdi - Mare Raidma „Viola”. Huvitav on seegi, et Jaan Tangsoo, kes leidis 2002. aasta võistlusel tunnustust käsikirjaga „Marukoer”, tuli eesti kirjandusse 1990. aasta romaanivõistlusega, kui märgiti ära tema käsikiri „Kroonukuue kütkes”, millest sai 1991. aastal autori debüütteos. Lisaks tõsteti 2002. aasta võistlusel esile hilisema, 2004. aasta võistluse esikohaomaniku Sass Henno käsikiri „Elu algab täna”, mis ilmus raamatuna alles 2006. aastal, pärast suure kära saatel ilmunud võiduromaani „Mina olin siin” ja lasteraamatut „Mereröövlimäng”. Kuna aga „Elu algab täna” riputati juba 2003. aastal internetti, loeksin sellegi romaanivõistluselt pärit esikteoste hulka.

2004. aastal esile tõstetute nimistust avastasin koguni viis debüüti. Kolmanda auhinna saanud Meelis Friedenthali nime võib enne seda leida küll mitme raamatu tiitellehe pöördelt, aga kujundaja või illustraatorina. „Kuldne aeg” on Friedenthali ilukirjanduslik debüüt, mille on nüüdseks muidugi varjutanud 2012. aastal ilmunud „Mesilased” - romaan, mis pälvis Euroopa kirjandusauhinna ning mis on hetkel üks rahvusvaheliselt edukamaid eesti kirjandusteoseid. Lisaks Friedenthali romaanile avaldasid 2005. aastal oma esimesed raamatud juba mainitud Eia Uus („Kuu külm kuma”) ning Ruth Vassel („Vihma vari”), 2006. aastal Jaan Aps („Tähtis kevad”) ja 2007. aastal Tarmo Sibrits („Kuldkuju”). Jällegi leiab 2004. aasta parimate tegijate hulgast ühe 1990 . aasta romaanivõistlusel tähelepanu pälvinud debütandi - Mae Antsu. Tema esikteosele „Mu pärnade aegu”, mis ilmus 1991. aastal, langes toona osaks ergutusauhind.

2006. aasta paistab debütantide mõttes eriti oluline, ehk just seetõttu, et kolme auhinnatu hulgas oli neid tervelt kaks: Tiina Laanem ja Olle Lauli. Lisaks veel mitteametliku neljanda koha pälvinud Peeter Helme, kelle käsikiri „Puudutus" vormus esikteoseks samuti 2007. aastal, ning Marion Andra, kelle „Vähemalt..." nägi trükivalgust 2008. aastal. Samal aastal toimunud romaanivõistlusel pälvis Andra käsikiri „Algolagnia” ühe kahest kolmandast auhinnast. Neljas 2006. aasta võistluselt pärit debütant oli Angela Hofberg romaaniga „Päev nagu elu”.

2008. aasta võistlus paistab küll silma uue põlvkonna autorite (Birk Rohelend, Marion Andra, Kurvitz, Robert Randma) osalusega, kuid otseselt debütante tuli esiletõstetute hulgast kolm: Kurvitz, Robert Randma romaaniga „Sigaret” ning Helju Pets romaaniga „Ônneõiteta sirelid”. Pole kindel, kui paljud mäletavad Randma romaani visuaalselt efektset esikaant ning tema programmilist sõnavõttu Sirbis, kus ta kirjutas muuhulgas nii: „Õun ei pea alati paiknema kausi keskel, see võib olla ka kausi kõrval, sest piirid laienevad pidevalt. Seetõttu ei saagi me lugeda tänapäevast teksti lähtuvalt neist reeglitest, mis on loonud meie peas kindla raamistiku, ja sellelt baasilt ei saa me laiemalt mõista ka tänapäeva noorte kunsti ja kultuuripilti" (Randma 2009). Randma sõnavõtt tekitas resonantsi, seda tsiteeris oma esimeses Sirbis avaldatud essees Mihkel Kunnus, kui ta võttis sapiselt lahata 
Mikk Pärnitsa romaani „Hundikutsikaeetika" ning selle kaudu terve kirjandusliku põlvkonna: „Seetõttu suhtusin ja suhtun ka Robert Randma manifestikesse nii veriselt: tajumine ei ole uus mäletamine, „kiire eriteemaliste slaidide vahetumine" ei ole uus narratiivsus, promiskuiteet ei ole uus truudus, lollus ei ole uus tarkus, erinev, aga võrdne" (Kunnus 2010). Nagu näha, hargneb siit üks huvitav põhimõtteline vastandus, nägemuste erinevus (mis ei tundu olevat siiani vaibunud), ning on ainult kahju, et Randma tundub olevat eesti kirjanduselust eemale tõmbunud.

2015. aasta võistlusel silmapaistnute hulgas on debütante olnud üllatavaltki vähe, kuigi selle põhjuseks võib osutuda tõsiasi, et osa käsikirju pole jõudnud veel raamatuks vormuda. Ainsaks debüüdiks liigitub praeguse seisuga Helve Undo „Mõtetes elatud elu”. Žüriilt tunnistähe saanud autorite hulgast tõotab tulla veel mõni debütant. Siiski jääb silma, et kõik auhinnatud - Kõomägi, Laur, Eelrand ja Ashilevi - on juba tuntud tegijad, näiteks Kõomägi on hetkel kahe romaani ja nelja jutukogu autor. Auhinnatute nimistu teeb antud kontekstis aga huvitavaks kahe pärjatu ilmselge romaanivõistluse taust. Märt Lauri debüütromaan „Appasionata” sai

\section{Kirjandus}

Kunnus, Mihkel 2010. Stepihundikutsika dialoogi ihkav monoloog. Uue põlvkonna arvustus. - Sirp 29. I, http:// www.sirp.ee/s1-artiklid/c7-kirjandus/ stepihundikutsika-dialoogi-ihkav-monoloog-uue-polvkonna-arvustus/

Randma, Robert 2009. Muutumine kui distsipliini surm? - Sirp 6. XI, http:// www.sirp.ee/s1-artiklid/c7-kirjandus/ muutumine-kui-distsipliini-surm/

T o m b e r g, Jaak 2014. Maailmaehitamise paranduslik ainelaulatus. - Sirp 9. I, http://www.sirp.ee/s1-artiklid/c7-kirjan-
Tänapäeva 2011. aasta romaanivõistlusel teise koha, Helen Eelrand on samuti pälvinud nimetatud kirjastuse võistlusel tunnustuse - 2013. aastal kolmanda koha.

Mida võib eelöeldu põhjal väita? Vahest seda, et romaanivõistlus paistab sobivat paljudele kirjanikele hüppelauaks, sissejuhatavaks teeotsaks eesti kirjandusse. Uue aastatuhande kontekstis võib öelda, et romaanivõistluse kaudu on eesti kirjandusse tulnud, võistluse abil oma positsioone võimendanud või oma jälje jätnud muljet avaldav hulk autoreid. Mõnedki neist on aastate jooksul neile osaks langenud tunnustust oma edasise tegevusega õigustanud - olgu siis romaanikirjanikena või mõnes teises kirjandusžanris. Tõsi, paljud autorid - näiteks Tohvri, Hargla, Ruitlane, Laanem, Friedenthal jt - on pärast võistlusel tähelepanu pälvimist loobunud selles osalemast (või vähemalt jääb selline mulje kõrvalt vaadates ning tulemusi jälgides). Ometi võib kokkuvõtteks järeldada, et romaanivõistlustel on eesti kirjanduselus kindlana tunduv, ennekõike verd värskendav, uusi tegijaid pakkuv koht.

\section{JAN KAUS}

dus/maailmaehitamise-paranduslik-ainelaulatus/

Vaher, Berk 2010. Vaeslapse käsi kiri: eesti proosa 2009. - Looming, $\mathrm{nr} 3$, lk 408-427.

Vint, Toomas 2010. Proosamaastik 2009, kaldu harrastuskirjanduse poole. - Sirp 16. IV, http://www.sirp.ee/s1-artiklid/ c7-kirjandus/proosamaastik-2009-kaldu-harrastuskirjanduse-poole/

Väljataga, Märt 2010. Oletusi ja kokkuvõtteid nullindate kirjandusest. Mõttevahetus: 00-ndad eesti kirjanduses. Looming, nr 5, lk 713-725. 